\title{
Zeitschrift
}

\author{
für die
}

\section{alttestamentliche Wissenschaft.}

\author{
Herausgegeben
}

voln

\section{BERNHARD STADE,}

\section{3.}

Dreizehnter Jahrgang.

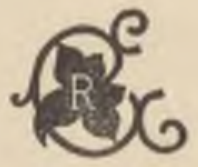

EV

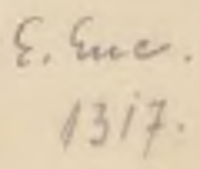

G i e s s e $n$.

J. Ricker'sche Buchhandlung. 1893. 


\title{
Ueber Bibelcitate in muhammedanischen Schriften.
}

\author{
Von I. Goldzilıer, Budapest.
}

Wenn wir in muhammedanischen Biographien in Bezug auf einige Gelehrte die Nachricht finden, dals dieselben im Taurât heimisch waren, so sind solche Mittheilungen in den seltensten Fällen ernst zu nehmen. Sie erscheinen gewöhnlich in so fabelhafter Umgebung und die Citate, mit denen die angeblichen Bibelkenner prunken, sind in der Regel so arge Erdichtungen, dals man gegen derartige Mittheilungen von berechtigtem Verdacht erfiillt wird. Wir müssen nur die Citate, die der berühınte Fachr al-dîn al-Râzî̀ aus der Tôra anführt, ansehen, um in diesem Urtheil bestärkt zu werden ${ }^{1}$ ). Zuweilen wird ketzerischen Leuten, um ihre Abirrung von der muhammedanischen Rechtgläubigkeit zu motiviren, das Studium der Religionsschriften anderer Bekenntnisse zugemuthet. Ismâîl b. Sa îd al-Kurdî in Aegypten stand wegen seines schonungslosen Sarkasmus im Rufe der Ketzerei. Man nannte ihn gewöhnlich Ismâ̂îl al-kâlir oder I. al-zindîk. Er soll vieles aus der Thora und den Evangelien auswendig gewulst

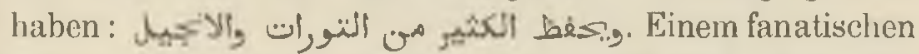
Zcitgenossen träumte einmal, dals Ismâîl sich gegen Lot

1) S. ZDMG, XXXII, p. 360, 384 vgl, auch Mafâtîl al-gejb

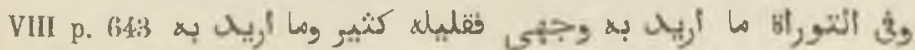

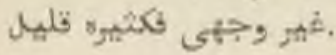


Schmähereden erlaubt hätte. Dieses Traumes wegen wurde Ismấîl in einen peinlichen Procefs verwickelt, der i. J. 720 d. H. mit der Hinrichtung Ismâêlls endete ${ }^{1}$ ).

Wir hahen bereits anderswo (ZDMG Bd. XXXII) weitläufiger auseinandergesetzt, dafs die Kenntnifs des Taurât bei den Muhammedanern bis in das IX.-X. Jhdt. Chr. völlig nur auf Hörensagen begründet war. Davon legt die Hadith-literatur vielfach Zeugnifs ab. Die Citate aus dieser Literatur und sonstige Beziehungen auf dieselbe sindso absurd und aus der Luft gegriffen, dafs sie nur auf die Unwissenheit der Informationsquellen der ersten muhammedanischen Generationen schliefsen lassen. Aus dem unverfälschten Buche der Kinder Aron's* welches als ein Theil der Tôra angefülı̣̂t wird, lälst man den jüdischen Gelehrten Abû Mâlik, der auch sonst (Jâkût IV p. 593, 1) aus dem Taurât eitirt, die Schilderung Muhammeds entnehmen ${ }^{2}$ ).

Schon in älterer Zeit scheinen solche Citate aus dem Taurât den Leuten bedenklich vorgekommen zu sein. Abú Hurejra erzählt einmal im Namen des Propheten, dafs ein jüdisches Geschlecht in alten Zeiten in Mäuse verwandelt worden sei. Beweis dafür, dals die Mäuse, wie die Juden keine Kamelmilch trinken. Von dem jüdischen Convertiten $K \mathrm{a}^{\mathrm{c}} \mathrm{b}$ befragt, ob er diese Nachricht wirklich vom Propheten habe, entgegnet er ihm spöttisch: *Lese ich

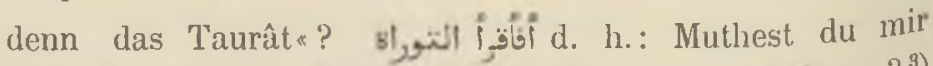
denn zu, unwahre Berichte unter die Leute zu bringen? ${ }^{3}$ )

1) Ibn IIaǵar al-Askalânî (Hschr. der Wiener Hofbibliothek) I. Fol. $208 \mathrm{a}$.

2) Ibn Haǵar, Is a ba IV, p. 322

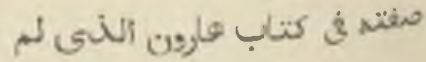

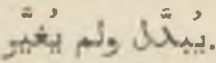

8) Al-Buchârî Bad' al-chalk Nr. 1f. Die muhammedanische Legende lälst Káb und Abû Hurejra in ein intimes Verhältnifs $z \not t$ einander treten; einmal hatten sie ein Zusammentreffen beim Sinatberge (Al-ț̂r), wo Ká b dem Abû H. Hadithe des Propheten, jenor diesem den Inhalt des Taurat mittheilt (Al-Nas â' 1 , Sunan I p. 126). 
Der Schwindel, den man mit Citaten aus dem Taurât trieb, entging nicht dem Gefühle der Gebildeten, welche diese dilletantischen Mittheilungen auf ihren Werth zurückzufïlıren

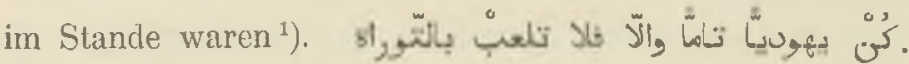
»Wenn du kein perfecter Jude bist, so spiele mit dem Taurât nicht * - lautet ein arabisches Sprichwort ${ }^{2}$ ).

Nicht selten weisen die aus dem Taurât entnommenen Citate, wo sie auf wirkliche Bibelstellen gegründet sind, ganz merkwïrdige Milsverständnisse auf. Zum Theil gilt dies von den Citaten jener Stellen, die man auf Nuhammed deutete $\left.^{8}\right)$. Aber sie beschränken sich niçht auf diesen Kreis. Eines der stärksten Beispiele dieser Art bietet uns der alte Koraninterpret Mugâhid (st. am Antange des II. Ihd.), ein Schüler des Ibn 'Abbâs. Derselbe überliefert die Num. 20, 7-13 erzahlte Begebenheit in folgender Weise:

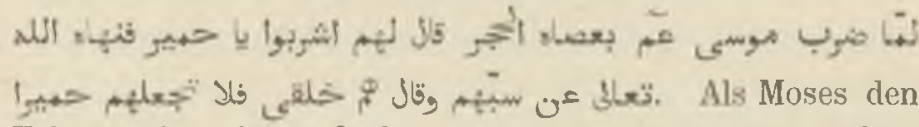

Felsen mit scinem Stabe schlug, sarte er zum Volke: Trinket ihr Esel! Da verbot ihm Gott, sie zu schmïhen. »Sie sind meine Geschöpfe, mache sie nicht zu Eseln * ${ }^{4}$ ). Man sicht, Mugâahid wurde durch jemanden informirt, der במקרים v. 10 mit טמצח verwechselte. Auch dafür giebt es viele Beispiele, dafs Nachrichten aus der israelitischen

1) Vgl. üher jüdische Mittheilungen, meine Muhamm. Studien II p. 137.

2) A I-M e jod̂́nî ed. Bûlâk II p. 101.

8) Vgl. Schreiner ZDMG. XLII p. 601. $626 \mathrm{ff}$.

4) Al-Sá rânî Kaśf al-ğ umma an ǵamî́ a l-umma (Kairo 1281) II 332. Das Wunder, das in jener Bibelstelle errählt wird, ist von den Muhammedanern an einen runden Felsen in Al-Lagún (sïdwestl. Galiläa) angeknüpft worden; aber ibre Legende lälst das Wunder an diesem Felsen durch den Patriarchen Abraham vollziehn. Jâ $\mathrm{k}$ t $\mathrm{IV}$ p. $351 \mathrm{Al}-\mathrm{Kaz}$ zîn î ed. Wüstenfeld II p. 172. 
Zeit ihre Entstehung der Milsverstehung oder falschen Deutung von wirklichen biblischen Daten verdanken.

Von dem »Genossen *, Ibn Mas'îd, wird folgende Notiz

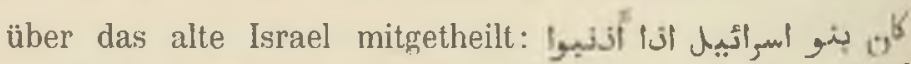

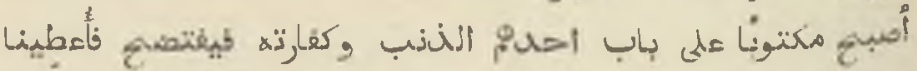

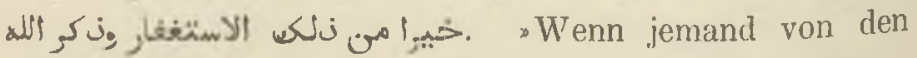
Banû Isrâ'ŝl eine Sünde beging, so ward auf die Thüre des Betreffenden die Sünde und die Sülınung derselben aufgeschrieben, so dals er dadurch beschämt wurde. Uns ist besseres als dies gegeben worden: die Bitte um Sündenvergebung und die Erwälınung Gotles* ${ }^{1}$ ). Es lälst sich nicht in Zweifel ziehen, dals bei dieser Mittheilung eine

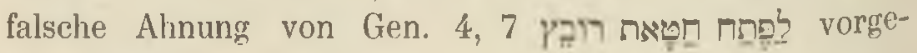
schwebt hat.

Vom IX.-X. Jhd. an bemerken wir eine sicherere Vertrautheit der muhammedanischen Theologen mit hiblischen Ilingen. Die grölsten Mifsverständnisse und fabelhafte Citate überfluthen zwar auch ferner die theologische Literatur; aber es begegnen uns dennoch Anzeichen dafür, dafs es sich ernstere Gelehrte angelegen sein liefsen, sich über das Taurât solider zu informiren, als es ihre Vorgänger thaten. Man bestrebte sich aus Uebersetzungen eingehendere Kenntnils vom jüdischen Gesetz zu holen. $\mathrm{A}$ bû Bekr al-Kaffâl (st. 336 d. H. $=947$ Chr.) bietet in weilläufiger Weise ein Citat aus Genes. 32, $25 \mathrm{ft}$ :

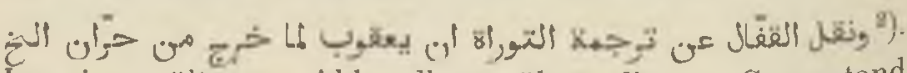
In einer älteren Abhandlung über diesen Gegenstand (p. 357) haben wir besonders Ibn Kutejba (st. 276 d. H. $=889 \mathrm{Chr}$.) als den ersten Muhammedaner genannt, bei dem uns correcte Citate aus dem Taurât begegnen.

1) Kasf a l-g umma I p. 404.

2) Bei Fachral-dîn al-Kâzî III p. \&. 
Wir konnten unser Urtheil damals nur auf einige Abschnitte seines durch Wüstenfeld herausgegebenen Handbuch der Geschichte * ${ }^{1}$ ) gründen.

Jedoch nicht nur in seinem historischen Werke benutzt I. K. correcte Citate aus dem Taurât. In einem theologischen Buche Muchtalif al-hadêth, in welchem er sich die Aufgabe stellt, die muhammedanische Tradition gegen dic Einwürfe der Rationalisten und Philosophen zu vertheidigen, begegnen wir einigen Anführungen aus dem P'entateuch. Das Taurât wird, ebenso wie das N. T., welches gleichfalls mehrere male angelührt ist ${ }^{2}$ ), zu dem Zwecke citirt, un nachzuweisen, dafs die von den Gegnern beanstandeten Traditionen Gedanken und Anschauungen enthalten, denen bercits in älteren Religionsschriften Ausdruck gegeben ward.

Die Citate des Ibn Katejba aus Taurât sind zweierlei Art. In alter Weise spricht auch er zuweilen Taurâtcitale nach, die in diesem Buche nicht vorkommen. So z. B. findet sich p. 349 unter der Anführung 8l,

1) Vgl. jetzt Marc. Lidzbarski, De propheticis, quae dicuntur legjenclis arabicis (Leps. 1893) p. 9 ff.

1) Hschr. der Leidener Universitcitsbibliothek, Cod. Warner

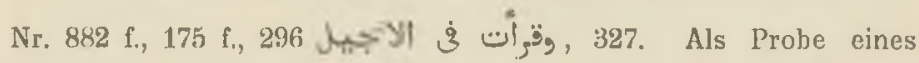
Evangeliencitates bei Ibn Kutejba geben wir hier die von ihm angefiilrte Uebersetzung zu Matth. 5, 33-37, womit der Traditionsspruch dals A Allăh zuletzt den Boden von Waǵg (betreten) haber, gerechtfertigt werden soll: Muchtalif al-hadîth p. 253

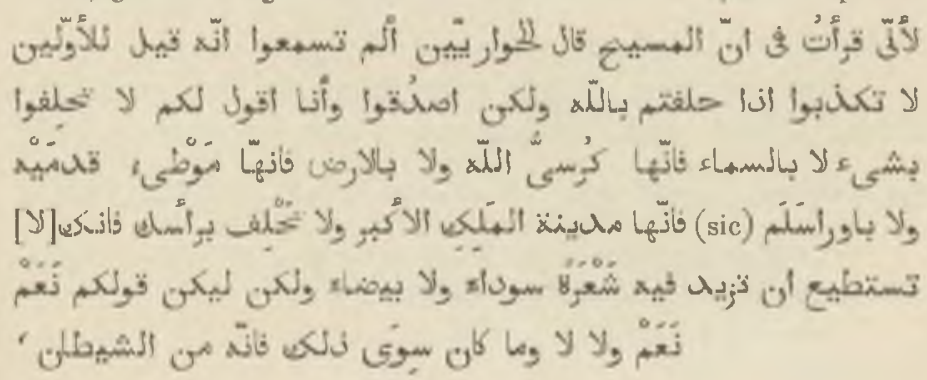


ein langes Stück, in welchem von der Schöpfung des Menschen und seiner Zusammensetzung aus den vier Temparamenten طب يليس سانغئن وبارن, (feucht, trocken, warm und kalt) weitläufig gesprochen wird. Den zeitgenössischen Aerzten Ajjûb und Hunejn spricht er es nach, dals in der Tô̂râ geschrieben sei, dals Elfenbein in Essig schwimme wie ein Fisch, und dals es als Amulet diene, welches auf die Schenkel einer Frau gebunden, die Wirkung habe,

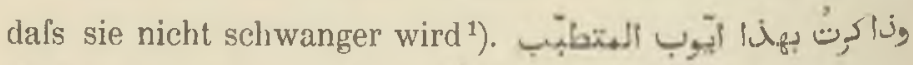

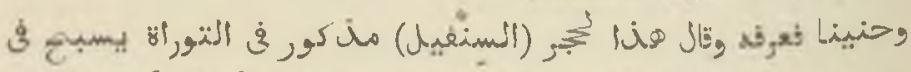

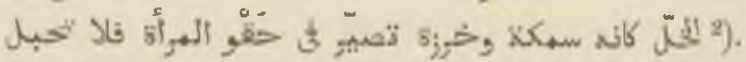

Ein ungenaues Citat ist auch folgendes. Ein Suti habe ihm den Inhalt von Exod. 20,5 aus einem ider älteren

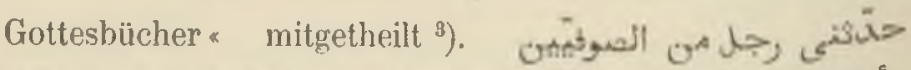

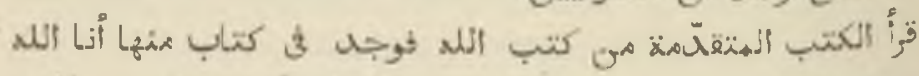
. Daraus ersehen wir, dals I. K. selbst nicht gar tief in die Tôrn-lectüre eindrang. Ueber die Genesis linaus scheint sich dieselbe nicht erstreckt zu haben; aus diesem Buche sind seine Citate im *Handbuch der Geschichte entlehnt. Im theologischen Werke, aus welchem wir hier schöpfen, finden wir einige jener Stellen wieder, namentlich ed. Wiistenf. p. 7 Z. 3 كis 4 bill وكاj. bis p. 8 Z, تراب mit folgenden Varianten: Z. 3

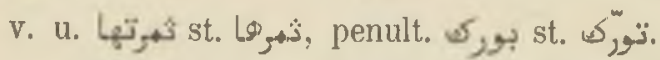

Dem letzteren Stück geht folgender im geschichtlichen Werke nicht enthaltener Passus voraus: p. 164

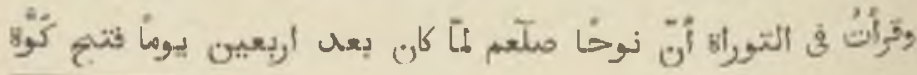

1) Al-Krazwîní I p. 401, Al-Damîrî II p. 278 oben, eignen diese Eigenschaft dem Mist des Elefanten zu.

2) Muchtalif al-had. p. 275.

$\left.{ }^{3}\right)$ ibid. p. 298. 


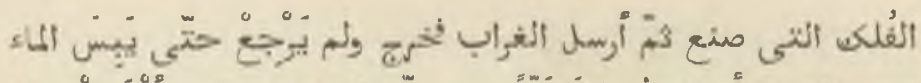

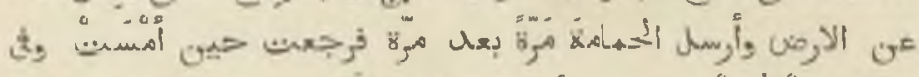

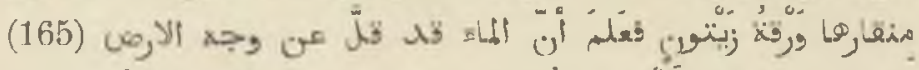

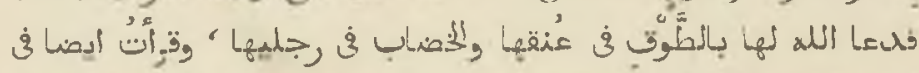

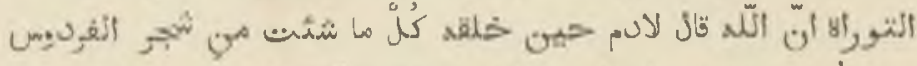

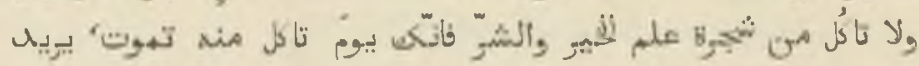

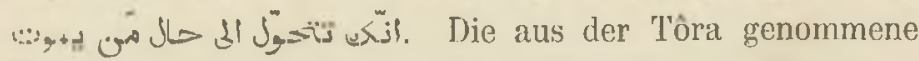
Erzählung ist, wie man sicht, mit agadischen Elementen untermischt.

Zum Schlusse erwähne ich noch ein apokryphisches Buch, welches Ibn Kutejba hier aus eigener Lectüre anführt: Unterredung des Ezra mit Gott. Daraus citirt er folgende Stelle ${ }^{1}$ ): $\rtimes 0$ Gott! du hast von den Thieren das Schaf erwählt, von den Vögeln die Taube, von den Pflanzen den Weinstock, von den Wohnorten Mekka und Jerusalem und von Jerusalem den heiligen Tempel * :

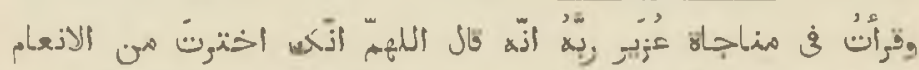

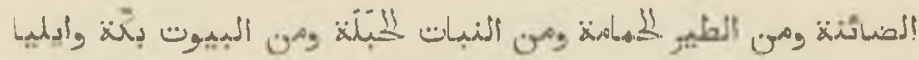
' Herr Professor Merx war so gütig, mir als Quelle dieses Citates das IV. Ezra-Buch Kap. 5 nachzuweisen.

1) Muchtalif al-hadith p. 375. 